Original Research Paper

\title{
Effect of Physical Treatments on the Promotion of Seed Germination in Green and Giant Foxtails
}

\author{
Inagaki Hidehiro and Sakakibara Takumi
}

Shizuoka University, Shizuoka, Japan

\author{
Article history \\ Received: 25-08-2020 \\ Revised: 19-10-2020 \\ Accepted: 20-10-2020 \\ Corresponding Author: \\ Inagaki Hidehiro \\ Shizuoka University, Shizuoka, \\ Japan \\ Email: inagaki.hidehiro@shizuoka.ac.jp
}

\begin{abstract}
The difficulty of breaking seed dormancy in Setaria (foxtail) species presents a problem in using them as model plants. In the present study, we observed the structure of the seed coat surface of two Setaria species, the green foxtail (Setaria viridis) and the giant foxtail (Setaria faberi), using an electron microscope. In addition, we tested the effects of physical treatment on Setaria seeds using four treatments: (1) Removing the outer seed coat, (2) removing the outer seed coat + mechanical scarification of the inner seed coat (the seeds were scarified using sand-paper with grit 350-2000), (3) removing the outer and inner seed coat and (4) No treatment (control). During the observation using electron microscope, we found a structure that was supposed to repel water (which is called the 'lotus effect'). We found that seed germination in Setaria species can be induced by removing the outer seed coat along with mechanical scarification of the inner seed coat (second treatment) as well as by removing the outer and inner seed coat (third treatment), whereas seed germination was not observed after removing only the outer seed coat and no treatment.
\end{abstract}

Keywords: Physical Treatment, Seed Germination, Setaria, Green Foxtail, Giant Foxtail

\section{Introduction}

Climate change is a great problem throughout the world, which is why $\mathrm{C}_{4}$ plants, which perform $\mathrm{C}_{4}$ type photosynthesis and exhibit high photosynthetic ability under conditions of high temperature, dryness and strong light in the summer, are increasingly drawing attention as climate change-tolerant species. $\mathrm{C}_{4}$ plants include important crops such as corn, sorghum and sugar corn and these plants are an important source of bio-energy (Acharya et al., 2017). However, typical $\mathrm{C}_{4}$ plants are not suitable for basic research of $\mathrm{C}_{4}$ plants because of their large size and because their cultivation requires a large-scale field (Eck and Swartwood, 2015). Consequently, Setaria (foxtail) species, such as the green foxtail (S. viridis) and the giant foxtail (S. faberi), which have small plant sizes, are drawing attention as possible $\mathrm{C}_{4}$ model plants (Doust et al., 2009; Brutnell et al., 2010; $\mathrm{Li}$ and Brutnell, 2011; Bennetzen et al., 2012; Eck and Swartwood, 2015; Acharya et al., 2017; Hodge and Doust, 2017; Hu et al., 2018). The green and giant foxtail are annual Poaceae weed species (GRIN, 2020) which possess some weed characteristics (i.e., 'weediness'), such as rapid growth, small plant size at the seed setting stage, prolific seed production and short life cycle (Baker, 1974). These characteristics are problematic for weed removal but are ideal for the use of these species as model plants (Sebastian et al., 2014). In addition, Setaria species would be useful as model plants because of their relatively small genome sizes (Brutnell et al., 2010). However, they have strong seed dormancy (Born, 1971; Banting et al., 1973; Dekker and Hargrove, 2002) and their germination is not uniform (Dekker and Hargrove, 2002; Dekker, 2003). Such difficulty in breaking seed dormancy makes them extremely inconvenient for use as model plants (Manthey and Nalewaja, 1987; Liu et al., 2003; Sebastian et al., 2014).

Researchers have tried to elucidate seed dormancy in Setaria species (Manthey and Nalewaja, 1987; Dekker and Hargrove, 2002; Liu et al., 2003; 2017; Mauro-Herrera et al., 2013; Sebastian et al., 2014; Amini et al., 2015a-b; Shu et al., 2015; Saha and Blumwald, 2016; Saha et al., 2016; Hodge and Doust, 2017) and they have concluded that the development of seed dormancy breaking methods is important issue in order to be able to utilize Setaria species as model plants (Mauro-Herrera et al., 2013; Qie et al., 2014; 
Sebastian et al., 2014; Muthamilarasan et al., 2015; Feng et al., 2016; Feldman et al., 2017; Huang et al., 2017; Liu et al., 2017).

In general, the storage of Setaria seeds in the dark under refrigerated conditions is effective for breaking their dormancy (Amini et al., 2015a; Acharya et al., 2017). However, this treatment requires several months for inducing germination (Sebastian et al., 2014). Therefore, chemical treatment methods, such as the liquid smoke treatment (Sebastian et al., 2014), gibberellic acid treatment (Acharya et al., 2017; Sebastian et al., 2014) and $\mathrm{KNO}_{3}$ treatment (Sebastian et al., 2014), have been proposed for inducing germination in a shorter period of time. However, it has been reported that the smoke liquid treatment has a harmful effect on seeds, resulting in a low germination rate (Acharya et al., 2017). In addition, the effect of any chemical treatments on seed germination requires several weeks, is unstable (Sebastian et al., 2014) and with these treatments, it is relatively difficult to achieve consistent and uniform germination (Acharya et al., 2017).

In the present study, we studied the surface structure of Setaria viridis and S. faberi seeds and we investigated the effects of four different physical treatments on the germination of their seeds.

\section{Materials and Methods}

\section{Seed Material and Observation of the Seed Surface Structure}

The seeds of green foxtail (Setaria viridis) and giant foxtail ( $S$. faberi) were collected from the field at Shizuoka University (Fujieda City, Japan) on November 8, 2019 and stored in a refrigerator. We observed the seed surface structure with a microscope (HITACHI, Tokyo, Japan: TM3030 Plus).

\section{Seed Germination after Physical Treatment}

The second lemma and the first glume of the seed were regarded as the outer seed coat and the second glume and the palea of the seed were regarded as the inner seed coat. In this experiment, the following four treatments were separately applied to the seeds of green and giant foxtail: (1) Removing the outer seed coat, (2) Removing the outer seed coat and mechanical scarification of the inner seed coat; the seeds were scarified with sand-paper (grit 350-2000), (3) Removing the outer and inner seed coat and (4) No treatment (control). Thirty seeds were put on a filter paper in a petri dish with a diameter of $90 \mathrm{~mm}$ and moistened with distilled water. The germination test was carried out at $25^{\circ} \mathrm{C}$ for $12 \mathrm{~h}$ per day under bright light conditions. Each treatment had five replications. The test started on November 26, 2019 and the final germination rate was calculated eight days after the start of the experiment, when no germination occurred for several days. Germination was defined as radical emergence.

\section{Germination and Data Analysis}

Arcsin transformed germination proportion was subjected to analysis of variance using Bell Curve for Excel 5.0 (Social Survey Research Information Co., Ltd., Tokyo, Japan). After conducting the analysis of variance, Tukey's multiple range test was used to detect significant differences among the treatments with a probability of $95 \%(\alpha=0.05)$.

\section{Results and Discussion}

\section{Seed Surface Structure}

Figure 1 shows an electron micrograph of green foxtail seeds and Fig. 2 shows an electron micrograph of the surface of their outer coat. On the surface of their outer coat, we observed a structure in which the protrusions were arranged in parallel (Fig. 2). Figure 3 shows an electron micrograph of green foxtail seeds with the outer seed coat removed and Fig. 4 shows an electron micrograph of the surface of their inner coat. On the surface of their inner coat, we observed a structure with a mesh-like vein and a projection with a hook at the intersection (Fig. 4). Figure 5 shows an electron micrograph of green foxtail seeds with the outer and inner seed coats removed and we observed several uneven areas. The same structure was also observed in the seeds of the giant foxtail (data not shown).

Microscopic reliefs on the seed surface are often known to provide effective water repellency called the 'lotus effect' (Barthlott and Neinhuis, 1997). The undulations found on the surface structure of the outer and inner seed coats of the two investigated species might have the 'lotus effect'.

\section{Seed Germination after Physical Treatments}

Figure 6 shows an electron micrograph of green foxtail seed with removing outer coat and inner coat treated with mechanical scarification. We confirmed that mechanical scarification of the inner seed coat damages the inner seed coat.

Figure 7 shows the results of the germination test of the green foxtail and the giant foxtail. In both species, seed germination was not observed after we removed only the outer seed coat. Germination was observed in both species when the outer seed coat was removed along with mechanical scarification of the inner seed coat, although the germination rate was low. Relatively higher germination rate was observed in both species when both the outer seed coat and the inner seed coat were removed. All germinated seeds were growing normally in the petri-dishes. In Setaria species, seed dormancy is considered to be a physiological factor and 
the breaking of this dormancy has mainly been studied using chemical treatments (Mauro-Herrera et al., 2013; Qie et al., 2014; Sebastian et al., 2014; Muthamilarasan et al., 2015; Feng et al., 2016; Feldman et al., 2017; Huang et al., 2017; Liu et al., 2017). On the other hand, as the present study showed that even though the germination rates were low, germination could be induced by physical treatment, it is possible that besides being related to physiological factors, dormancy is related to physical factors as well. Seed coat impermeability is an important factor in seed dormancy and in the present study, the scarification treatment was used to break seed dormancy by breaking this impermeability. However, the impermeability of the seed coat have been reported in species with hard-coated seeds, such as legumes (Sy et al., 2001; Vilela and Ravetta, 2001; Travlos et al., 2007) and there are few reports of the impermeability of the seed coaton Poaceae seeds. The present study is one of the few studies in which germination of Poaceae seeds was induced by mechanical scarification treatment.

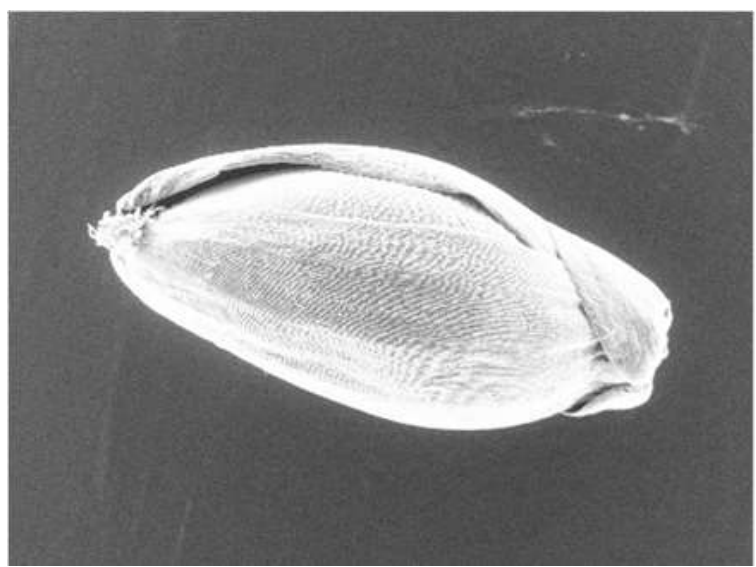

Fig. 1: Electron micrograph of a green foxtail seed (magnification $60 \times$ )

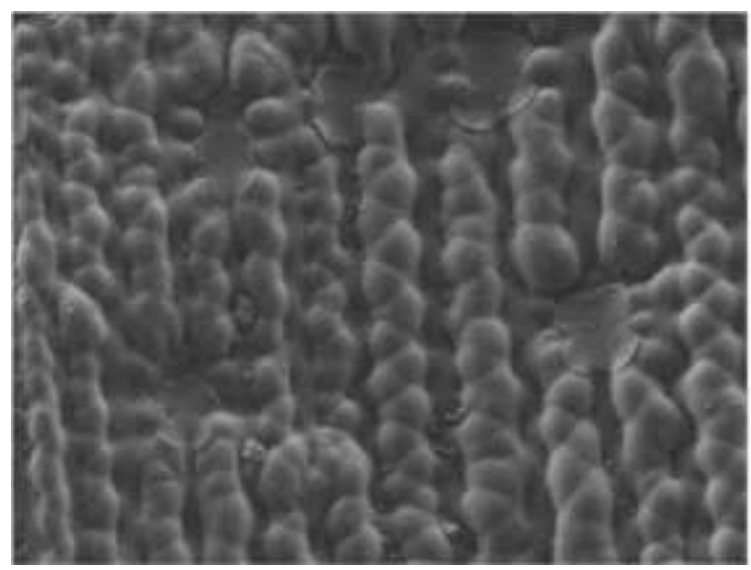

Fig. 2:Electron micrograph of the outer seed coat of the green foxtail (magnification $2000 \times$ )

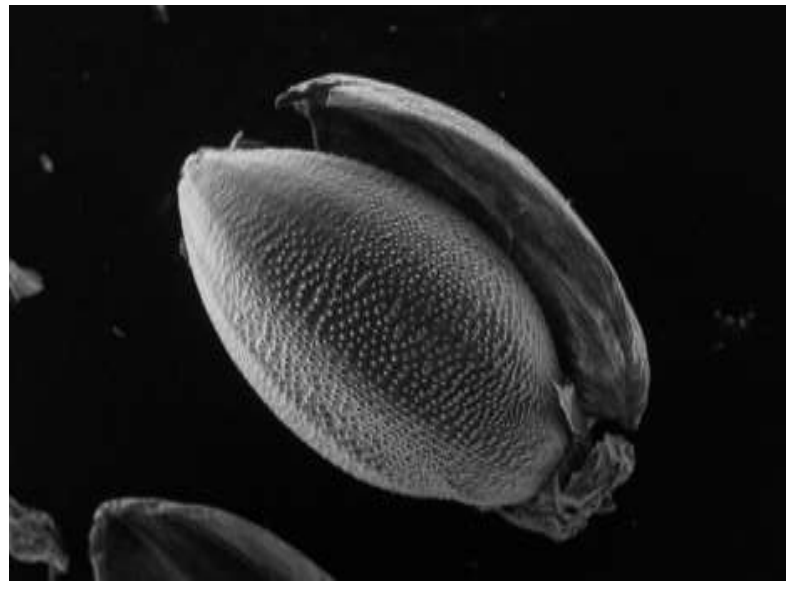

Fig. 3:Electron micrograph of green foxtail seed with outer seed coat removed (magnification $60 \times$ )

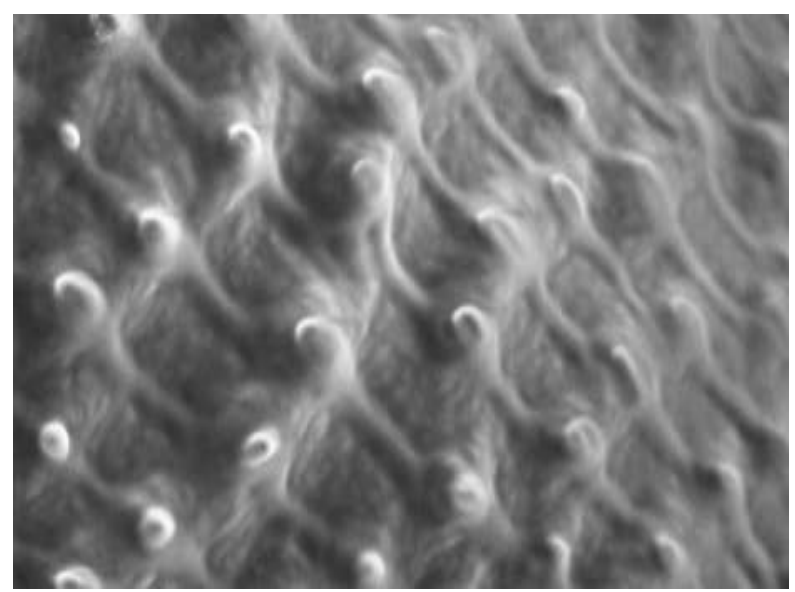

Fig. 4: Electron micrograph of the inner seed coat of the green foxtail (magnification $1000 \times$ )

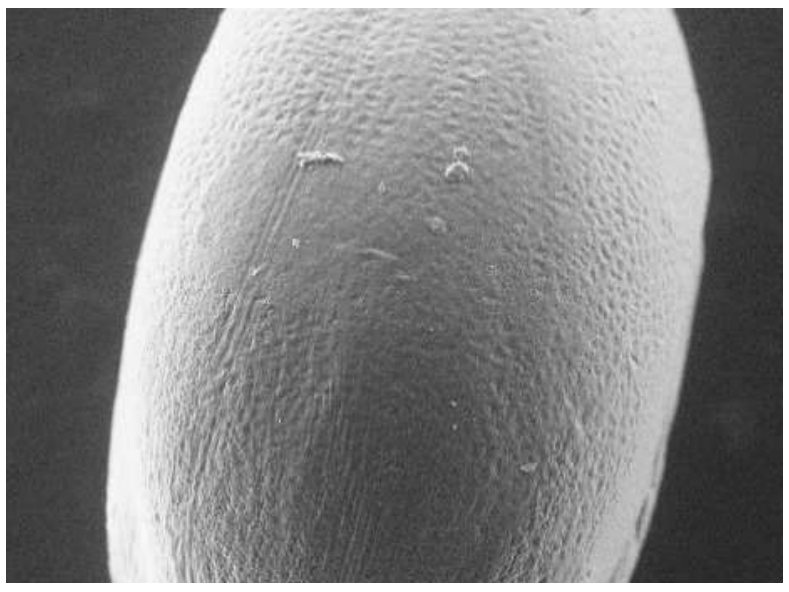

Fig. 5: Electron micrograph of green foxtail seed with outer and inner seed coat removed. (magnification $180 \times$ ) 


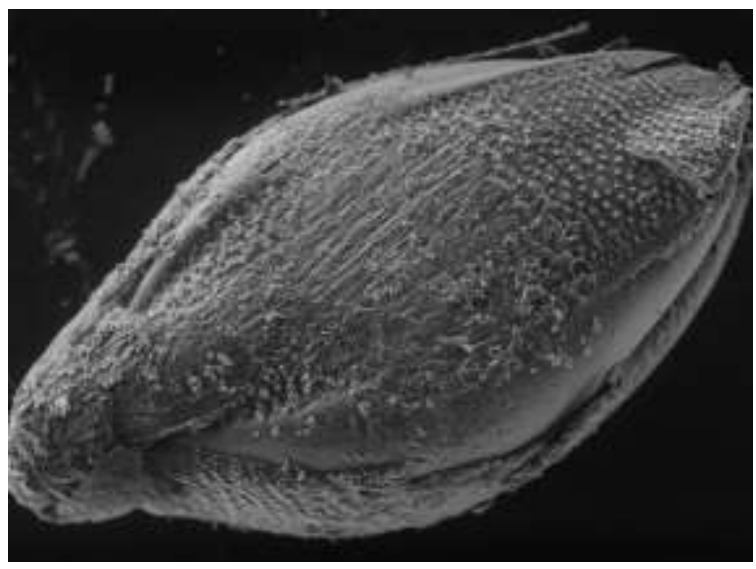

Fig. 6: Electron micrograph of green foxtail seed with outer seed coat removed and treated with mechanical scarification of the inner seed coat (magnification $100 \times$ )

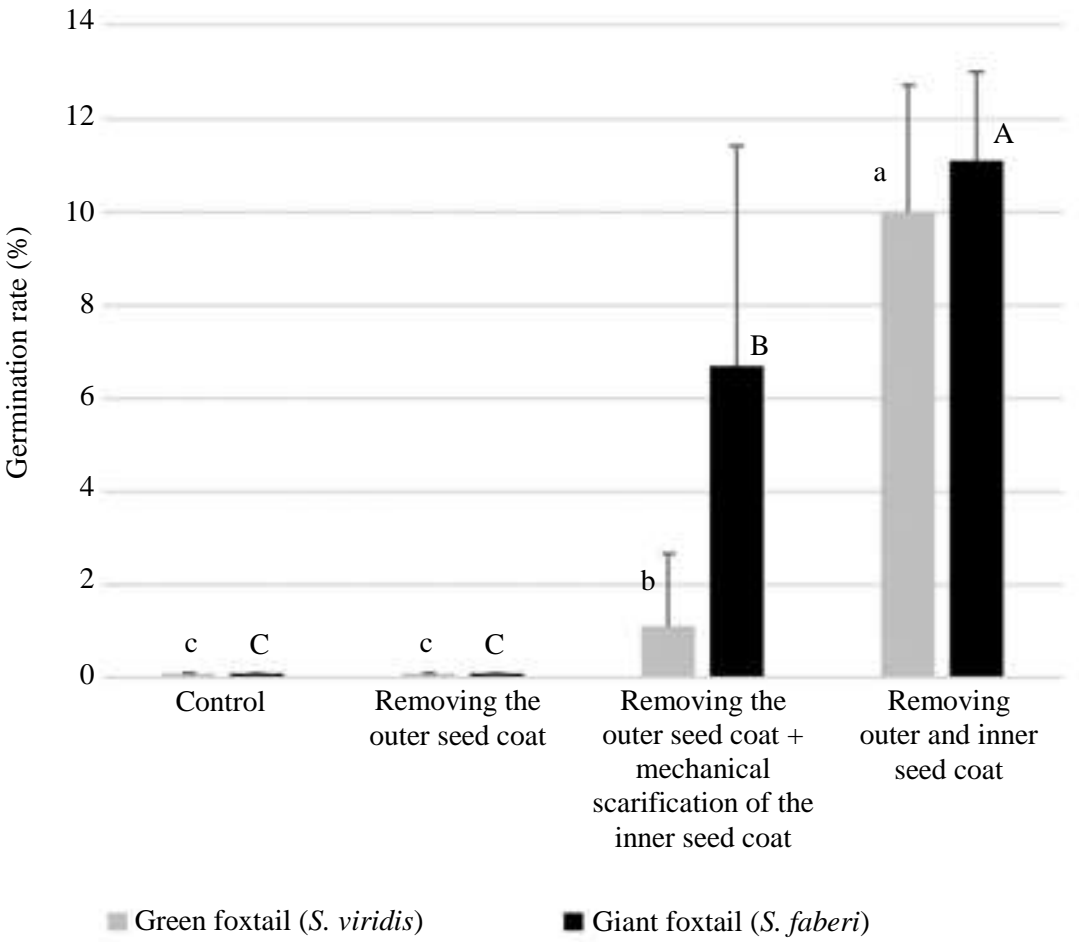

Fig. 7: The effect of different physical treatments on Setaria seed germination error bars represent Standard Deviations $( \pm$ SD). Different letters indicate significant differences $(\mathrm{P}<0.05)$ according to Tukey's honestly significant difference test. Different uppercase letters indicate significant differences among treatments in the green foxtail and different lowercase letters indicate significant differences among treatments in the giant foxtail

In addition, this physical factor of their seed dormancy may be related to the 'lotus effect' because of the structure with protrusions on the outer and inner coat of Setaria species seeds. Our results indicated that the physical treatment method is an effective method for breaking dormancy in Setaria species. However, because the germination rate of Setaria species was low, further studies are required to improve this aspect.

\section{Conclusion}

Setaria (foxtail) species possess certain characteristics that make them suitable for being a model $\mathrm{C}_{4}$ plants; some of these characteristics include rapid growth, small plant size at the seed setting stage, prolific seed production, fast life cycle and small genome size. However, the difficulty of breaking seed dormancy is a 
problem for their use as model plants. Although many studies have been conducted on the development of different methods for breaking this seed dormancy, many of them used chemical treatments and were not very successful. In the present study, we observed a structure that was presumed to repel water via the 'lotus effect'. Subsequently, we studied the effects of physical treatments, including scarification and removal of seed coats, on the dormancy of Setaria seeds. We found that the seed germination of Setaria species can be induced by two tested physical treatments: (1) by removing the outer seed coat along with mechanical scarification of the inner seed coat and (2) by removing both the outer and the inner seed coat. These results supported the idea of the utilization of Setaria species as model plants. However, a new problem which occurred in the present study is that the germination rate of the treated seeds was not high enough. In the future, it will be necessary to develop a method to further increase their germination rate by modifying the physical treatments or by combining physical and chemical treatments.

\section{Author's Contributions}

All authors contributed equally to this work.

\section{Ethics}

This article is original and contains unpublished material. The corresponding author confirms that all of the other authors have read and approved the manuscript and no ethical issues involved.

\section{References}

Acharya, B. R., Roy Choudhury, S., Estelle, A. B., Vijayakumar, A., Zhu, C., Hovis, L., \& Pandey, S. (2017). Optimization of phenotyping assays for the model monocot Setaria viridis. Frontiers in plant science, 8, 2172.

Amini, V., Zaefarian, F., \& Rezvani, M. (2015a). Interspecific variations in seed germination and seedling emergence of three Setaria species. Brazilian Journal of Botany, 38(3), 539-545.

Amini, V., Zaefarian, F., \& Rezvani, M. (2015b). Effect of pre-chilling and environmental factors on breaking seed dormancy and germination of three foxtail species. Acta agriculturae Slovenica, 105(2), 269-278.

Baker, H. G. (1974). The evolution of weeds. Annual review of ecology and systematics, 5(1), 1-24.

Banting, J. D., Molberg, E. S., \& Gebhardt, J. P. (1973). Seasonal emergence and persistence of green foxtail. Canadian Journal of Plant Science, 53(2), 369-376.
Barthlott, W., \& Neinhuis, C. (1997). Purity of the sacred lotus, or escape from contamination in biological surfaces. Planta, 202(1), 1-8.

Bennetzen, J. L., Schmutz, J., Wang, H., Percifield, R., Hawkins, J., Pontaroli, A. C., ... \& Jenkins, J. (2012). Reference genome sequence of the model plant Setaria. Nature biotechnology, 30(6), 555-561.

Born, W. V. (1971). Green foxtail: seed dormancy, germination and growth. Canadian Journal of Plant Science, 51(1), 53-59.

Brutnell, T. P., Wang, L., Swartwood, K., Goldschmidt, A., Jackson, D., Zhu, X. G., ... \& Van Eck, J. (2010). Setaria viridis: a model for C4 photosynthesis. The Plant Cell, 22(8), 2537-2544.

Dekker, J., \& Hargrove, M. (2002). Weedy adaptation in Setaria spp. V. Effects of gaseous environment on giant foxtail (Setaria faberii)(Poaceae) seed germination. American Journal of Botany, 89(3), 410-416.

Dekker, J. (2003). The foxtail (Setaria) species-group. Weed science, 51(5), 641-656.

Doust, A. N., Kellogg, E. A., Devos, K. M., \& Bennetzen, J. L. (2009). Foxtail millet: a sequencedriven grass model system. Plant physiology, 149(1), 137-141.

Eck, J. V., \& Swartwood, K. (2015). Setaria viridis. In: Agrobacterium protocols Volume 1, Third edition, Wang, K., (Ed.), (pp: 57-67). Humana Press, Totowa, NJ.

Feldman, M. J., Paul, R. E., Banan, D., Barrett, J. F., Sebastian, J., Yee, M. C., ... \& Leakey, A. D. (2017). Time dependent genetic analysis links field and controlled environment phenotypes in the model C4 grass Setaria. PLoS genetics, 13(6), e1006841.

Feng, Z. J., Xu, Z. S., Sun, J., Li, L. C., Chen, M., Yang, G. X., ... \& Ma, Y. Z. (2016). Investigation of the ASR family in foxtail millet and the role of ASR1 in drought/oxidative stress tolerance. Plant cell reports, 35(1), 115-128.

GRIN. 2020. Agricultural Research Service (ARS), United States Department of Agriculture (USDA). Germplasm Resources Information Network. https://www.ars-grin.gov/

Hodge, J. G., \& Doust, A. N. (2017). Morphological development of Setaria viridis from germination to flowering. In Genetics and Genomics of Setaria (pp. 161-175). Springer, Cham.

Hu, H., Mauro-Herrera, M., \& Doust, A. N. (2018). Domestication and improvement in the model $\mathrm{C} 4$ grass, Setaria. Frontiers in Plant Science, 9, 719.

Huang, P., Jiang, H., Zhu, C., Barry, K., Jenkins, J., Sandor, L., ... \& Brutnell, T. P. (2017). Sparse panicle1 is required for inflorescence development in Setaria viridis and maize. Nature plants, 3(5), 1-6. 
Li, P., \& Brutnell, T. P. (2011). Setaria viridis and Setaria italica, model genetic systems for the Panicoid grasses. Journal of experimental botany, 62(9), 3031-3037.

Liu, Z., Li, X., Li, R., Jiang, D., \& Cao, C. (2003). A comparative study on seed germination of 15 grass species in Keeqin Sandyland. Ying yong sheng tai xue $b a o=$ The journal of applied ecology, 14(9), 1416-1420.

Liu, K., Qi, S., Li, D., Jin, C., Gao, C., Duan, S., ... \& Chen, M. (2017). TRANSPARENT TESTA GLABRA 1 ubiquitously regulates plant growth and development from Arabidopsis to foxtail millet (Setaria italica). Plant Science, 254, 60-69.

Manthey, D. R., \& Nalewaja, J. D. (1987). Germination of two foxtail (Setaria) species. Weed Technology, 302-304.

Mauro-Herrera, M., Wang, X., Barbier, H., Brutnell, T. P., Devos, K. M., \& Doust, A. N. (2013). Genetic control and comparative genomic analysis of flowering time in Setaria (Poaceae). G3: Genes, Genomes, Genetics, 3(2), 283-295.

Muthamilarasan, M., Bonthala, V. S., Khandelwal, R., Jaishankar, J., Shweta, S., Nawaz, K., \& Prasad, M. (2015). Global analysis of WRKY transcription factor superfamily in Setaria identifies potential candidates involved in abiotic stress signaling. Frontiers in plant science, 6, 910.

Qie, L., Jia, G., Zhang, W., Schnable, J., Shang, Z., Li, W., .. \& Diao, X. (2014). Mapping of quantitative trait locus (QTLs) that contribute to germination and early seedling drought tolerance in the interspecific cross Setaria italica× Setaria viridis. PloS one, 9(7), e101868.
Sebastian, J., Wong, M. K., Tang, E., \& Dinneny, J. R. (2014). Methods to promote germination of dormant Setaria viridis seeds. PLoS One, 9(4), e95109.

Saha, P., \& Blumwald, E. (2016). Spike-dip transformation of Setaria viridis. The Plant Journal, 86(1), 89-101.

Saha, P., Sade, N., Arzani, A., Wilhelmi, M. D. M. R., Coe, K. M., Li, B., \& Blumwald, E. (2016). Effects of abiotic stress on physiological plasticity and water use of Setaria viridis (L.). Plant Science, 251, 128-138.

Shu, K., Meng, Y. J., Shuai, H. W., Liu, W. G., Du, J. B., Liu, J., \& Yang, W. Y. (2015). Dormancy and germination: How does the crop seed decide?. Plant Biology, 17(6), 1104-1112.

Sy, A., Grouzis, M., \& Danthu, P. (2001). Seed germination of seven Sahelian legume species. Journal of Arid Environments, 49(4), 875-882.

Travlos, I. S., Economou, G., \& Karamanos, A. I. (2007). Germination and emergence of the hard seed coated Tylosema esculentum (Burch) A. Schreib in response to different pre-sowing seed treatments. Journal of Arid Environments, 68(3), 501-507.

Vilela, A. E., \& Ravetta, D. A. (2001). The effect of seed scarification and soil-media on germination, growth, storage and survival of seedlings of five species of Prosopis L.(Mimosaceae). Journal of Arid Environments, 48(2), 171-184. 